\title{
Atuação da sociedade no Conselho Nacional de Turismo: demandas e rede de relacionamentos
}

\author{
Acting of the society in the National Tourism Council: demands and network of relationships
}

Actuación de la sociedad en el Consejo Nacional de Turismo: demandas y red de relaciones

Joana Luiza Oliveira Alencar Mestrado em Administração pela Universidade de Brasília Estatutário do Instituto de Pesquisa Econômica Aplicada http://lattes.cnpq.br/3016201478500388 joana.alencar@ipea.gov.br

Edgar Reyes Junio Doutorado em Administração pelo Universidade do Vale do Rio dos Sinos Professor pela Universidade de Brasília http://lattes.cnpq.br/4600683588964302 edreyes@unb.br

Resumo: Para lidar com a complexidade das políticas, a gestão pública tem passado por experiências de interação com os mais diversos segmentos da sociedade organizada. $\mathrm{O}$ objetivo deste artigo é analisar o conteúdo da atuação da sociedade junto às políticas públicas de turismo no espaço do Conselho Nacional de Turismo (CNTUR) e a rede que se forma a partir desse conteúdo. Realizou-se a análise documental, cujas fontes foram 46 atas de reuniões ordinárias do Conselho, de 2003 a 2015. A leitura de cada ata identificou: as demandas apresentadas, o conselheiro que propõe cada uma delas e os conselheiros que as comentam. A partir das proposições e reações elaborase a rede de relações do conselho, identificando localização de cada ator, centrais e periféricos. Assim podemos visualizar que muitos dos atores presentes no conselho nunca se manifestaram e poucos são responsáveis pela maioria das proposições, especialmente o Ministério do Turismo e o indicado da presidência da república.

Palavras chave: Conselhos, Redes sociais, políticas públicas, turismo

\begin{abstract}
In order to deal with the complexity of politics, public management has undergone experiences of interaction with the most diverse segments of organized society. The objective of this article is to analyze the content of the society's actions along with the public politics of tourism in the National Tourism Council (Conselho Nacional de Turismo - CNTUR) and the network formed onwards this content. A documentary analysis was carried out, whose sources were 46 minutes of the ordinary meetings of the CNTUR, from 2003 to 2015. The reading of each minutes identified demands presented, the counselor who proposes each one and those who comment them. The network of relations of the council is elaborated from the propositions and reactions, identifying the location of each actor, central and peripheral. Thus, we can see that many of the actors present in the council never manifested themselves and few are responsible for mos of the propositions, especially the Tourism Department and the nominee of the presidency of the republic. Keywords: Councils, social networks, public politics, tourism
\end{abstract}

Resumen: Para lidiar con la complejidad de las políticas, la gestión pública ha pasado por experiencias de interacción con los más diversos segmentos de la sociedad organizada. El objetivo de este artículo es analizar el contenido de la actuación de la sociedad junto a las políticas públicas de turismo en el espacio de Consejo Nacional de Turismo (CNTUR) y la red que se forma a partir de ese contenido. Se realizó el análisis documental, cuyas fuentes fueron 46 actas de reuniones ordinarias del Consejo, de 2003 a 2015. La lectura de cada acta identificó: las demandas presentadas, el consejero que propone cada una de ellas y los consejeros que las comentan. A partir de las proposiciones y reacciones se elabora la red de relaciones del consejo, identificando la ubicación de cada actor, centrales y periféricos. Así, podemos ver que muchos de los actores presentes en el consejo nunca se manifestaron y pocos son responsables de la mayoría de las proposiciones, especialmente el Ministerio de Turismo y el indicado de la presidencia de la república. Palabras clave: Consejos, Redes sociales, políticas públicas, turismo.

Texto completo em português: http://www.apgs.ufv.br Full text in Portuguese: http://www.apgs.ufv.br

\section{INTRODUÇÃO}

O Conselho Nacional de Turismo (CNTUR) é um órgão colegiado que integra o chamado núcleo estratégico da gestão em turismo do governo federal, junto com o Ministério do Turismo (MTUR) e o Fórum Nacional dos Secretários e Dirigentes Estaduais do Turismo (FORNATUR). Já possuiu diversas composições desde sua criação, sempre com a presença de representantes do governo federal e de representantes de entidades não governamentais que atuam no setor. (CNTUR, 2016)

Sua atuação dá-se por meio de reuniões ordinárias trimestrais e da atuação em câmaras temáticas. O conselho é integrado em 2016 por 75 representações, dentre instituições públicas e entidades privadas, que indicam seus representantes titulares e suplentes, todas elas podem participar das reuniões ordinárias. A ideia dessas reuniões é que conselheiros exponham suas questões e demandas ao governo que, por sua vez, articula encaminhamentos e respostas, e que os conselheiros possam também apresentar as atividades importantes em suas respectivas linhas de atuação. (CNTUR, 2016)

Durante o período de análise, o conselho possuía caráter consultivo, ou seja, suas decisões são formalmente consideradas como apoio às decisões do ministério, mas não são necessariamente implementadas.
Mesmo assim, estudos apontam que o poder de intervenção do conselho na Política Nacional de Turismo é significativo, ou seja, suas decisões costumam ser consideradas quando da tomada de decisão pelo ministério, especialmente no que se refere à inclusão de temas na agenda governamental (Brandão, 2010, 2014; CNTUR, 2016).

Cavalcanti (2006) no primeiro estudo que tratou diretamente do CNTUR, entendeu que lá está presente toda a representação do setor turismo no Brasil, consequentemente, os atores que juntos poderiam auxiliar na legitimação e implementação das políticas públicas propostas para a área. Ela tenta perceber como cada grupo atribui funções ao conselho. A partir dessa análise, entende que o Estado considera-o como uma assessoria ao processo de governança, na medida em que a aproximação com a sociedade permite captar melhor as características das diversas questões públicas e, por consequência, aumentando as chances de que as políticas públicas sejam efetivas.

Outra função prática observada pela autora é a de legitimar a atuação do Estado, assim, o CNTUR é visto como um espaço formalizado para legitimação de política pública. Já sob o ponto de vista dos conselheiros, a análise citada indica que eles o consideram como um espaço institucional, 
no qual os grupos de interesses disputam pela imposição de posições próprias a cada segmento.

Quanto à questão do CNTUR atuar para legitimar decisões, Oganauskas (2014) compara o conselho reativado em 2003 com o criado em 1966, ainda durante o período ditatorial. Segundo ela, ao aderir à prática de unicamente legitimar decisões, eles assemelham-se na medida em que focam exclusivamente no desenvolvimento econômico do turismo, desconsiderando seu papel democratizante.

De acordo com a legislação vigente, dentre as competências atuais do CNTUR é possível destacar elementos que ligam o turismo a: avaliação de políticas, democracia, geração de renda e redução de desigualdades, desenvolvimento do turismo interno, atração de turismo do exterior, sustentabilidade ambiental, social e cultural, legislação turística. Entre as catribuições, a questão da democracia está ligada à democratização da gestão. (BRASIL, 2008)

O CNTUR possui representantes de quase todo o empresariado da área, e quanto à representação profissional, parece haver um déficit de proporcionalidade na representação, pois existem três entidades representantes de profissionais do setor, as quais as não estatais são proporcionais às estatais. $O$ regimento interno do Conselho Nacional de Turismo determina, ao contrário dos outros conselhos citados, que os próprios conselheiros são responsáveis por pagar despesas com diárias e passagens para comparecimento às reuniões da junta. (CNTUR, 2009)

Estudos consideram que 0 aumento de cadeiras no conselho entre 2003 e 2008 mostra uma disposição para ampliar a capacidade de escuta e participação. No entanto, ponderam a inexistência de participação popular, pois se a população não está ativa nos fóruns de discussão local, as demandas não têm como chegar ao conselho nacional. Em crítica à gestão do turismo brasileiro, a autora pontua que a falta de participação popular no CNTUR e nos espaços locais que existem pode gerar políticas que não correspondem às necessidades sociais e ao interesse coletivo. (Brandão, 2010)

\section{FUNDAMENTOS TEÓRICOS}

A relação entre Estado e sociedade, por meio de instituições compostas por integrantes de ambos, tem sido uma realidade nas democracias, e os desafios para tornar esses espaços representativos e efetivos estão na agenda política. Assim, conhecer as formas pelas quais a sociedade relaciona-se com ele e utilizar ferramentas teóricas disponíveis para isso, pode ser útil na organização e aperfeiçoamento dessa relação, tanto por parte do Estado, como da sociedade.

Os estudos que utilizam análise de redes sociais têm investigado questões como sua caracterização em ambientes colaborativos; troca de conhecimentos e aprendizagem; impacto dos atores da rede em resultados de políticas públicas. Alguns buscam influenciar a produção de novos estudos que unam o conhecimento de estrutura de rede com ações e características dos sujeitos que a compõe (Burt, Kilduff \& Tasselli, 2013; Tasselli, 2015; Cândido, Sacomano \& Côrtes, 2015).

Em análise de rede, as relações são consideradas elementos fundamentais da sociedade. São mais do que as negociações que acontecem por meio delas. Ao estudar redes é possível identificar associações e posições de cada ator do campo. E, assim, analisar a influência que cada um possui, na medida em que essas estas orientam escolhas e dão acesso ao poder. (Hanemman, 2005; Donati, 2010)
Dessa forma, descreve a maneira como um ator insere-se na rede relacional à medida que a ele são impostas restrições e oferecidas oportunidades. Aqueles que enfrentam menos limitações e têm mais oportunidades estão em posições estruturais favoráveis, o que significa obter intercâmbios favoráveis e receber certa deferência dos que estão em outras posições. Atores com muitos vínculos têm mais alternativas de satisfazer suas necessidades, e assim, são menos dependentes de outros indivíduos, bem como podem obter mais do grupo. (Hanemman, 2005)

Segundo a análise de redes, o contexto social compõe-se de várias delas de relacionamentos, oriundas de diversas fontes. A representação gráfica de uma rede é denominada sociograma,os sujeitos são os vértices conectados entre pares, por linhas, e as conexões significam relações. A estrutura observada com a visualização da rede é formada por nós e vínculos. Enquanto estes estabelecem uma ligação entre um e outros atores, aqueles mostram as posições de cada agente e possibilitam verificar a estrutura geral de relações. Para isso, são necessárias informações acerca dos limites da rede, dos vínculos, do tipo e contexto de sua formação. Os vínculos obedecem a fluxos, que determinam a direção ou sentido. Quando o nó não o possui, ele está solto na rede. A partir disso, é possível descrever associação entre padrões de relações interpessoais e associá-los a resultados específicos. (Marques, 1999; Velázquez, 2005; Borgatti \& Cross, 2003; Nooy, 2003; Burt et al, 2013)

Atitudes e estratégias dos atores são influenciadas pela estrutura geral da rede e pela posição que ocupam. Aqueles que enfrentam menos restrições e têm mais oportunidades estão em categorias estruturais favoráveis, o que significa obter intercâmbios positivos. A posição também influencia os planos e perspectivas diante do mundo (Marques, 1999; Hanemman, 2005).

Atores com muitos vínculos têm mais alternativas de satisfazer suas necessidades, e assim, são menos dependentes de outros indivíduos, além disso, podem obter mais do conjunto da rede. Ao contrário de outros métodos de pesquisa que tem como foco os sujeitos e suas características, as redes sociais centram-se nas relações. Isso significa que os elementos estudados são selecionados propositalmente, tendo em vista que existem vínculos entre eles. Assim, a perspectiva de redes contribui para o entendimento do poder social. ao considerá-lo como inerentemente relacional. Nessa perspectiva, ele é visto como um conceito estreitamente ligado à centralidade, propriedade fundamental das estruturas sociais. $O$ domínio é consequência dos padrões de relação, assim, um indivíduo só tem poder se existem outros que permitam que o ele seja exercido. (Hanemman, 2005; Bonafont, 2004)

Ingold \& Leifeld, (2016) explicam que nas redes de políticas existem poder institucional e estrutural, eles podem ser percebidos ao estudar a configuração da rede social. Em estudo recente, esses autores concluíram que características institucionais e estruturais têm impacto na capacidade de influência na política pública na medida em que interferem na forma como cada ator é percebido nesse processo.

Há três propostas de entendimentos acerca padrões possíveis nas redes: a primeira, diz que os atores as formam a partir dos aspectos pessoais e entendimentos próprios. A outra, é de que elas é que moldam as pessoas, e a terceira visão faz um misto das duas anteriores e conclui que elas se complementam. Assim, para analisar resultados individuais, é necessário considerar a estrutura social na qual o indivíduo está inserido, 
da mesma forma, observar uma mudança na rede social implica em considerar as características dos indivíduos que a compõe (Tasselli, 2015).

Normalmente, as redes possuem atores centrais que localizam-se numa posição que permite acessar e difundir informações com mais facilidade em relação aos outros. Tal centralidade trata dos agentes individuais e sua posição na estrutura. Há também o conceito de centralização que se refere à descrição da rede como um todo (Nooy, Mrvar \& Batagel, 2005; Velázquez, 2005).

É possível observar que a centralidade de uma rede é pelos graus de centralidade, de intermediação e pela centralidade de autovetor. O grau de intermediação considera que um ator é mais central se for importante como intermediário entre outros atores. Quando a pessoa é necessária para que uma informação flua na rede, ela é central naquela rede. (Nooy et al, 2005; Velázquez, 2005)

\section{METODOLOGIA}

Este trabalho baseia-se em pesquisa documental, aquela feita em documentos de natureza não analítica e por fontes variadas (Silveira \& Gerhardt, 2009). Assim, a combinação inicia com um estudo qualitativo de análise daqueles, examinar-se-á as atas do CNTUR para identificação de informações sobre o conteúdo e a quantidade de demandas discutidas no período de tempo considerado.

Foi realizada a pesquisa documental em todas as atas de reunião ordinária do conselho no período de 2003 a 2015, além de serem coletadas e sistematizadas as informações referentes às demandas discutidas em cada reunião e atores que levaram e discutiram cada uma delas. A partir desses dados, foi elaborada a estrutura da rede e identificação de atores centrais por meio de grau de centralidade, intermediação e autovetor.

A leitura de cada ata identificou: as demandas levadas para discussão no conselho, o conselheiro que propõe cada uma e os que a comentam. Considera-se como demanda todos os pedidos, assuntos, propostas que forem levados ao CNTUR durante as reuniões ordinárias, que permitam um encaminhamento por ele, e que tenham provocado reação.

Após coleta e sistematização, foi possível construir a rede de relações existente no CNTUR e visualizar a posição dos conselheiros: centrais e periféricos, como base nas demandas e nos debates por elas gerados. A rede social do conselho permitirá visualizar seus atores mais ativos no período estudado - 2003 a 2016. Localizadas as pautas, identificar-se-á os agentes que propõem e discutem cada uma delas. Esse apoio é o indicativo de que existe uma relação entre eles. Durante a análise das atas os dados eram tabulados considerando que "1" representa que houve manifestação em relação à demanda apresentada e "0" representa a ausência de manifestação para a mesma demanda.

Identificadas demandas e atores institucionais demandantes - órgãos do governo, associações empresariais ou profissionais-, foi possível realizar a construção da rede de relacionamentos existente no interior do conselho, na qual mostra quem está ligado entre si e aponta os atores centrais. Os estudos de rede incluem todos os agentes situados em um determinado limite, ou seja, aqueles que compõe a situação estudada são considerados unidades de observação. (Hanemman, 2005; Velázquez, 2005; Bonafont, 2004)

O grau de centralidade indica o quanto um ator está ligado aos outros de forma direta. $O$ de intermediação considera que um agente é mais central se for importante como intermediário entre os demais. Assim, é a capacidade que 0 ator tem para ser o elo entre dois nós, este é também chamado "ponte". Quando a pessoa é necessária para que uma informação flua na rede, ela é central naquela rede. Tal centralidade deve-se ao controle que tem sobre a comunicação que ali acontece. Mede-se a intermediação ao contar quantas vezes o nó aparece no caminho entre dois outros nós da rede. Já a centralidade de autovetor mostra os sujeitos centrais a partir da estrutura geral da rede, mostrando o quanto eles mantêm contatos distribuídos por todos os grupos inseridos (Nooy et al, 2005; Velázquez, 2005; Reyes Junior, 2012).

\section{ANÁLISE DE DADOS}

Nas 46 reuniões, cujas pautas foram analisadas, duzentas demandas foram discutidas pelos conselheiros. Considera-se como tal todos os pedidos, assuntos, propostas que foram expostos durante as reuniões ordinárias do CNTUR que foram objeto de debate, estão registradas em ata e requerem um encaminhamento. A leitura de cada documento irá identificar: as solicitações levadas para discussão no conselho, o conselheiro que as propõe e os que as comentam.

São propostas de todo o período de nova atuação do conselho e tiveram encaminhamentos diversos. As questões coletadas, além de terem sido apresentadas nas reuniões plenárias do CNTUR, geraram reação de pelo menos uma pessoa. Assim, o mapeamento das demandas nas atas está baseado nos das conversas que aconteceram a partir das solicitações.

Após identificação e sistematização, as demandas discutidas no conselho de 2003 a 2015 e registradas em atas de reuniões ordinárias foram classificadas em seis tipos: 67 são demandas setoriais diversas, 47 sobre normas legais vigentes no setor turismo, 40 sobre medidas relacionadas ao Sistema Nacional de Turismo, 20 sobre capacitação profissionais ou pesquisas na área de turismo no Brasil, 19 a respeito de financiamento e orçamento e 7 sobre o funcionamento do conselho. Cada um desses tipos será detalhado na sequência.

Normas Legais Vigentes no Setor de Turismo

Dentre as demandas identificadas, 47 estão relacionadas às normas legais, o que inclui criação de leis, decreto, regulamentos. Considera-se também, o aperfeiçoamento, cumprimento ou regulamentação de atividades ou normas vigentes. As solicitações por criação de normas legais versam sobre assuntos trabalhistas, setoriais e de gestão do setor turismo, exemplos: "Elaboração do Projeto de Lei que possibilite aos trabalhadores a opção de tirar férias em até três períodos separados", "elaboração de um Plano Nacional do Turismo, com metas para 2015", "regras para navios internacionais na costa brasileira e regularização dos cruzeiros".

As discussões acerca de aperfeiçoamento de normas legais vigentes incluem pedidos de mudanças em decretos, leis, resoluções e portarias que atendam a setores específicos. Exemplos: "Inserção do turismo no DecretoLei $n^{\circ}$ 2.233", "Mudança na lei da balança - peso do ônibus deve poder chegar pelo menos a $30.000 \mathrm{~kg}$ ", "Mudança na legislação de licença de transporte, do turismo rodoviário, junto ao Departamento Nacional de Estradas de Rodagem (DNER)".

Também com intenção declarada de melhorar a aplicação de normas, há demandas por revisão e concessão. Um exemplo com potencial polêmico é o requerimento por "flexibilização da legislação de parques nacionais", que requer revisão de licenças para mineradoras utilizarem 
parques nacionais ao mesmo tempo em que atividades turísticas são proibidas ou restritas.

Quanto aos debates em torno da regulamentação de normas legais, é possível observar em metade deles a questão dos guias turísticos: idade mínima para exercício da profissão, regulamentação do exercício profissional de turismólogos e da lei que reconhece a ocupação. Outros temas levantados foram transporte marítimo, bingos e cassinos.

Houve colocações pelo cumprimento de leis, um exemplo é o pedido de articulação com o Conselho Nacional dos Direitos da Criança e do Adolescente (CONANDA) para verificação da lei que trata da permanência de crianças em hotéis. Foram expostos também pedidos de revogação de leis, apoio a projetos de lei e organização do setor turismo para influenciar votações no poder legislativo nacional e subnacionais em assuntos de interesse do setor turismo.

Por fim, cabe destacar as demandas situadas em torno da lei geral do turismo (Lei n. 11.771/2008). Aprovada em 2008 e discutida no conselho desde 2003, ela define atribuições do governo federal no planejamento, desenvolvimento e estímulo ao setor turismo. Solicitou-se desde mudanças pontuais sobre assuntos diversos, tais como hospedagem, profissionais da área e albergues, até questões mais gerais como aprimorar, rever, regulamentar e modificar aspectos da lei como um todo.

Medidas relativas ao Sistema Nacional de Turismo

As medidas relativas ao Sistema Nacional de Turismo incluem propostas sobre estratégia, articulação com outros órgãos, sugestões de pauta a serem iniciadas pelo Ministério do Turismo (MTUR), programas específicos em andamento, propostas de ação e gestão interna do ministério, totalizam quarenta demandas. Alguns temas repetem-se nas atas analisadas.

Demandas que apontam mecanismos estruturais para encaminhar os processos de trabalho e alcance de metas do ministério foram denominadas como de estratégia. Dentre elas, destacam-se as discussões sobre criação do Sistema Nacional de Turismo, de setor de inteligência para estabelecimento de prioridades no MTUR e o fortalecimento do conselho e fóruns nas deliberações do setor de turismo.

As conversas a respeito da necessidade de diálogo e atuação com outros órgãos também foram frequentes no CNTUR. A maioria dos debates citava especificamente o órgão com o qual deveria se estabelecer uma relação e o objetivo dela. Por exemplo, a discussão sobre "articulação do MTUR com o Ministério do Trabalho para viabilizar contratação de mão de obra temporária", esteve presente por mais de uma vez nas reuniões do conselho, assim como, "manter parceria com o congresso nacional". Outras citam a necessidade de articulação com um objetivo definido, porém não citam atores específicos, como, por exemplo, "integrar ministérios para qualificar a política de turismo".

Propostas de pautas a serem priorizadas pela gestão do MTUR, bem como propostas de ação imediata também foram registradas. Aqui considera-se solicitações por apoio a fóruns, planos de atuação conjunta, campanhas temáticas como por exemplo, a campanha pela infância e juventude e contra exploração sexual, amplamente debatida no conselho. Entre as propostas de ação, há requisições como a realização da $1^{\text {a }}$ conferência nacional de turismo, reiterada ao longo do tempo, solicitações de divulgação mais ampla de trabalhos desenvolvidos na área do turismo, como exemplo "Apresentar obras em infraestrutura do MTUR para divulgar o trabalho do ministério". Além disso, requerem criação de instrumentos mais específicos no alcance de objetivos postos, tais como "criar instrumentos específicos com reflexos no combate à prostituição infantil e o tráfico de drogas em áreas turísticas".

Por fim, foram observadas demandas que tratam de programas ou políticas públicas desenvolvidas pelo MTUR. O programa "Viaja mais melhor idade" foi defendido por mais de três vezes, com solicitações de apoio. O programa de apoio ao turismo no interior do país - Vai Brasil - foi apontado como portador de grande potencial para ativar a economia. Pedidos de aperfeiçoamento de sistemas de gestão também estão incluídos nessa categoria, sistemas como Sistema Integrado de Gestão do Turismo (SIGTUR), e o de Cadastro de pessoas que atuam na cadeia produtiva do turismo (CADASTUR) e do Fundo Geral de Turismo (FUNGETUR). Ainda no campo gestão, houve a demanda por realização de concurso público para o ministério do turismo.

\section{Capacitação ou pesquisas}

Foram discutidas 20 demandas relacionadas às requisições de pesquisas ou estratégias de capacitação profissional para o setor de turismo no Brasil, além da necessidade de bancos de dados confiáveis sobre o setor turismo no Brasil. Há também demandas por estudos específicos para desenvolvimento da mão de obra para o turismo, situação do setor hoteleiro e avanço em pesquisas na área de forma geral. Outras sugestões são a confecção do mapa do turismo, análise de programas de educação formal para inserir assuntos relativos à área, criação de banco de projetos para o desenvolvimento do turismo e financiamento de estudos para o desenvolvimento do setor.

Já a questão da qualificação da mão de obra e aperfeiçoamento de programas existentes nesse sentido, bem como críticas a eles, foram objeto de discussão com citações sobre cursos de guia turístico, do mesmo modo que a formalização da atividade em âmbito nacional, estadual e municipal. Há sugestões para criação de uma rede de capacitação profissional e institucional na área, dentre outras estratégias no mesmo sentido, citando por diversas vezes o Programa Nacional de Acesso ao Ensino Técnico e Emprego (Pronatec), e especificamente os voltados para eventos como copa e olimpíadas. Citou-se também a demanda por conscientizar o turista da formalização do setor de guias turísticos e a preparação para novos formatos de hospedagem, como o "cama e café".

\section{Financiamento e orçamento}

Sobre financiamento e orçamento, foram identificadas 19 demandas, a maioria sobre requisição de crédito ou de financiamento. Sete tratam de créditos específicos, como os ligados a programas como o Programa de Desenvolvimento do Turismo no Nordeste - PRODETUR/NE. Há também pedidos de financiamento para áreas específicas como agências de viagem, setor de eventos, camping, hospedagem e também para o turismo municipal. As solicitações gerais de financiamento referem-se ao setor de forma ampla, como criação de crédito para todas as atividades turísticas e maior atenção do setor econômico.

As demandas dirigidas aos bancos públicos também seguem a orientação de pedir priorização do turismo, bem como ampliação das linhas de crédito. Umas das solicitações sugere maior articulação entre a câmara temática de financiamento do conselho e os bancos públicos. Estão representados no CNTUR os seguintes bancos: Banco do Brasil, Caixa 
Econômica Federal, BNDES, Banco da Amazônia (BASA). Duas requisições, ainda, defendem reserva de receitas provenientes de impostos específicos para investimentos em turismo.

\section{Demandas setoriais}

Aqui estão incluídas demandas relativas aos setores que estão diretamente representados no conselho, totalizando 44 ,e também as que envolvem setores mais amplos do que os representados no conselho, 23. As discussões sobre solicitações provenientes de setores representados no CNTUR tratam de assuntos ligados aos serviços de aviação, hospedagem, entretenimento, turismo nacional, cruzeiros, sustentabilidade e infância.

Sobre 0 atendimento nos aeroportos, discutiu-se ao longo do período a necessidade de aperfeiçoar o atendimento, garantir a segurança, ampliar e qualificar o espaço físico. Nesse sentido, é citada a conveniência de articulação entre MTUR, Infraero e secretarias estaduais de turismo. A preservação do mercado de companhias aéreas também foi discutida, incluindo a questão da abertura para empresas estrangeiras, a quantidade de voos domésticos e ampliação dos equipamentos de empresas nacionais. Ainda houve questionamentos acerca do alto valor da passagem aérea.

A respeito do turismo nacional, as discussões centraram-se no cuidado com o turismo rodoviário e desenvolvimento da atividade turística regional e comunitária, de modo a incentivar viagens dentro do país. Houve discussões sobre estratégias para desenvolver a aviação nacional.

Legalizar casas de bingo, alterar períodos de férias e valorizar as categorias eventos e parques temáticos foram temas tratados a partir de demandas levadas ao conselho. Ainda como entretenimento considera-se a demanda pela inclusão de bares e restaurantes em programas do MTUR.

As questões relativas a cruzeiros também foram levadas para discussão no conselho por meio de solicitações por regularização da situação legal e infraestrutura portuária. Foram requeridos, também, benefícios para o setor hoteleiro e ajuda na promoção da hospedagem via camping durante eventos como copa do mundo.

As discussões sobre meio ambiente no CNTUR tiveram como foco questões polêmicas como flexibilização de regras de preservação ambiental para exploração de atividades turísticas, mudanças na faixa de preservação ambiental e utilização de áreas de preservação permanente. Discutiu-se turismo sustentável e infância, promoção internacional do turismo, concessão de visto para estrangeiro e certificados do MTUR.

Questões setoriais mais amplas totalizam 23 demandas registradas. Um exemplo é a solicitação de segurança pública em áreas turísticas, tema que diz respeito a mais do que interesses pontuais e requer atuação de diversos órgãos públicos e sociedade em conjunto.

Demandas por facilitação na emissão de vistos também foram apresentadas e discutidas, assim como solicitações pontuais como, por exemplo, a busca de solução para a Varig e cancelamento da concorrência para o hotel de Foz do Iguaçu. Outras apontam para conservação de espaços com potencial turístico como indicação da Amazônia como um dos monumentos da humanidade, atuação do Instituto do Patrimônio Histórico e Artístico Nacional (IPHAN) na preservação dos monumentos históricos de Fernando de Noronha e o trem do corcovado, no Rio de Janeiro.

Por fim, foram realizadas demandas para apoio a eventos específicos também, como Fórum Mundial de Turismo para Paz e Desenvolvimento
Sustentável e eventos de promoção internacional em geral. Além das questões relativas a copa do mundo.

\section{Funcionamento do conselho}

Por fim, 5 demandas geraram algum debate no período analisado e tratavam especificamente de questões internas ao próprio CNTUR: recuperação do conselho, inclusão de órgãos públicos e da sociedade no conselho, apoio a gestores do MTUR, engajamento do CNTUR nos Escritórios Brasileiros de Turismo no exterior. Sobre funcionamento das câmaras temáticas do conselho foi registrado o pedido por maior integração da Câmara de Financiamento e Investimento do CNTUR com o próprio Ministério do Turismo.

\section{DISCUSSÃO}

Das 75 entidades que compõe o conselho, 40 tiveram a iniciativa de propor questões para debate e encaminhamento, de acordo com as atas analisadas. Dessas, 34 são da sociedade, ou seja, nesse caso empresariais ou profissionais. Somente 6 entidades pertencentes ao poder público foram proativas no sentido de levar demandas ao conselho. $O$ ministério destaca-se como principal proponente, levou 37 temas que foram discutidos no período em análise. Os 2 ocupantes das cadeiras de indicação da Presidência da República, contados como uma única representação levaram 18 propostas para debate. Outra representação governamental foi a terceira que mais levou propostas às reuniões ordinárias do conselho -o Fórum de Secretários Estaduais, com 10 propostas. As outras três representações do poder público consideradas proativas no conselho trouxeram quantidades bem menores de demandas no mesmo período: Instituto Brasileiro de Turismo (Embratur) e o Banco Nacional de Desenvolvimento Econômico e Social (BNDES), com duas demandas, e a Agência Nacional de Aviação Civil (ANAC), com uma.

Já as 34 entidades da sociedade consideradas proativas no conselho, apresentaram juntas um total de 124 demandas, ou seja, uma média de 3,6 solicitações por entidades e uma moda de 2 requerimentos, referentes à oito entidades. As que mais propuseram demandas foram as três únicas representantes de profissionais, a Associação Brasileira de Bacharéis de Turismo (ABBTUR) com 10, a Federação Nacional dos Guias de Turismo (FENAGTUR) levou 9 e Confederação Nacional dos Trabalhadores em Turismo e Hospitalidade (CONTRATUH) com 8 .

No quadro 1, é possível observar as entidades que levaram maior quantidade de propostas ao conselho ao longo do período estudado, consta do apêndice 3 a lista com todas as entidades que levaram propostas e a respectiva quantidade:

Fundada em 1978, a Associação Brasileira de Bacharéis em Turismo (ABBTUR) foi a entidade não governamental que mais levou propostas às reuniões do conselho - 10 ou 5\%-, no entanto, não foi considerada central. Isso significa que não se encontra no grupo das entidades que possuem maior número de relações diretas na rede de relações do conselho, porém, a ABBTUR está entre as entidades que possuem um grau razoável de intermediação. Dentre as funções que Ihe são atribuídas, está a de reunir e representar os bacharéis de turismo de todo o território nacional. (ABBTUR, 2016)

A FENAGTUR é a segunda entidade não governamental com maior número de questões propostas segundo as atas analisadas - 9 questões 
ou $4 \%$. Existem atualmente 16 estados da federação filiados à FENAGTUR: Acre, Alagoas, Amapá, Bahia, Espirito Santo, Paraná, Maranhão, Minas Gerais, Mato Grosso do Sul, Mato Grosso, Paraíba, Pernambuco, Rio
Grande do Norte, Rio Grande do Sul, Sergipe, São Paulo. (FENAGTUR, 2016)

Quadro 1: Principais entidades proponentes de demandas

\begin{tabular}{|l|l|c|c|}
\hline Entidade & Segmento & Demandas propostas & $\%$ de demandas \\
\hline Ministério do Turismo & & 37 & $19,07 \%$ \\
\hline Indicação da Presidência da República & Governo & 18 & $9,27 \%$ \\
\hline FORNATUR & Governo & 10 & $5,15 \%$ \\
\hline ABBTUR & Governo & 10 & $5,15 \%$ \\
\hline FENAGTUR & Profissional & 9 & $4,63 \%$ \\
\hline CONTRATUH & & 8 & $4,12 \%$ \\
\hline ABAV & Profissional & 7 & $3,60 \%$ \\
\hline ABRARJ & Profissional & 7 & $3,60 \%$ \\
\hline BRAZTOA & Empresarial & 6 & $3,09 \%$ \\
\hline ABRAJET & Empresarial & 6 & $3,09 \%$ \\
\hline
\end{tabular}

Representante das operadoras de turismo desde 1989, a Associação Brasileira das Operadoras de Turismo (BRAZTOA) tem cerca de 90 empresas filiadas. Elas pertencem às áreas de excursões, recepção, produção de roteiros turísticos e assistência ao turista (BRAZTOA, 2016). Com a mesma quantidade de proposições, a Associação Brasileira de Jornalistas de Turismo (ABRAJET), criada em 1957, tem como filiados 350 jornalistas especializados em turismo. (ABRAJET, 2016). BRAZTOA e ABRAJET levaram ambas 6 demandas, o que representa $3 \%$ das demandas levadas ao conselho no período estudado.

Cabe destacar a atuação das entidades representantes de profissionais, dentre as 75 organizações que compõe o conselho, somente 3 representam profissionais do setor: CONTRATUH, que atua para as mais diversas categorias do setor e a ABBTUR e FENAGTUR, que representam, respectivamente, turismólogos e guias de turismo. A CONTRATUH pertence ao grupo das entidades centrais e também das que propõe maior quantidade de demandas. ABBTUR e FENAGTUR estão entre as que levaram demandas às reuniões do conselho com maior frequência.

\section{RESULTADOS}

Denominamos ator, cada instituição do poder público ou da sociedade - empresarial ou profissional - que compõe o conselho. Após a identificação das solicitações, a associação entre os atores que discutiram cada uma delas leva à rede de relações cujos nós são os atores e a participação na discussão de uma demanda produz os vínculos que ligam um ao outro. A organização das demandas mostra os agentes que agem de forma propositiva com mais frequência e a visualização da rede mostra quais são os centrais. Esta, representada na figura1, é composta por todos os atores institucionais que compõe a lista mais atual de conselheiros do CNTUR, de novembro de 2015 (39 da sociedade e 30 do governo).

Figura 1: Rede de relações do CNTUR de 2003 a 2015

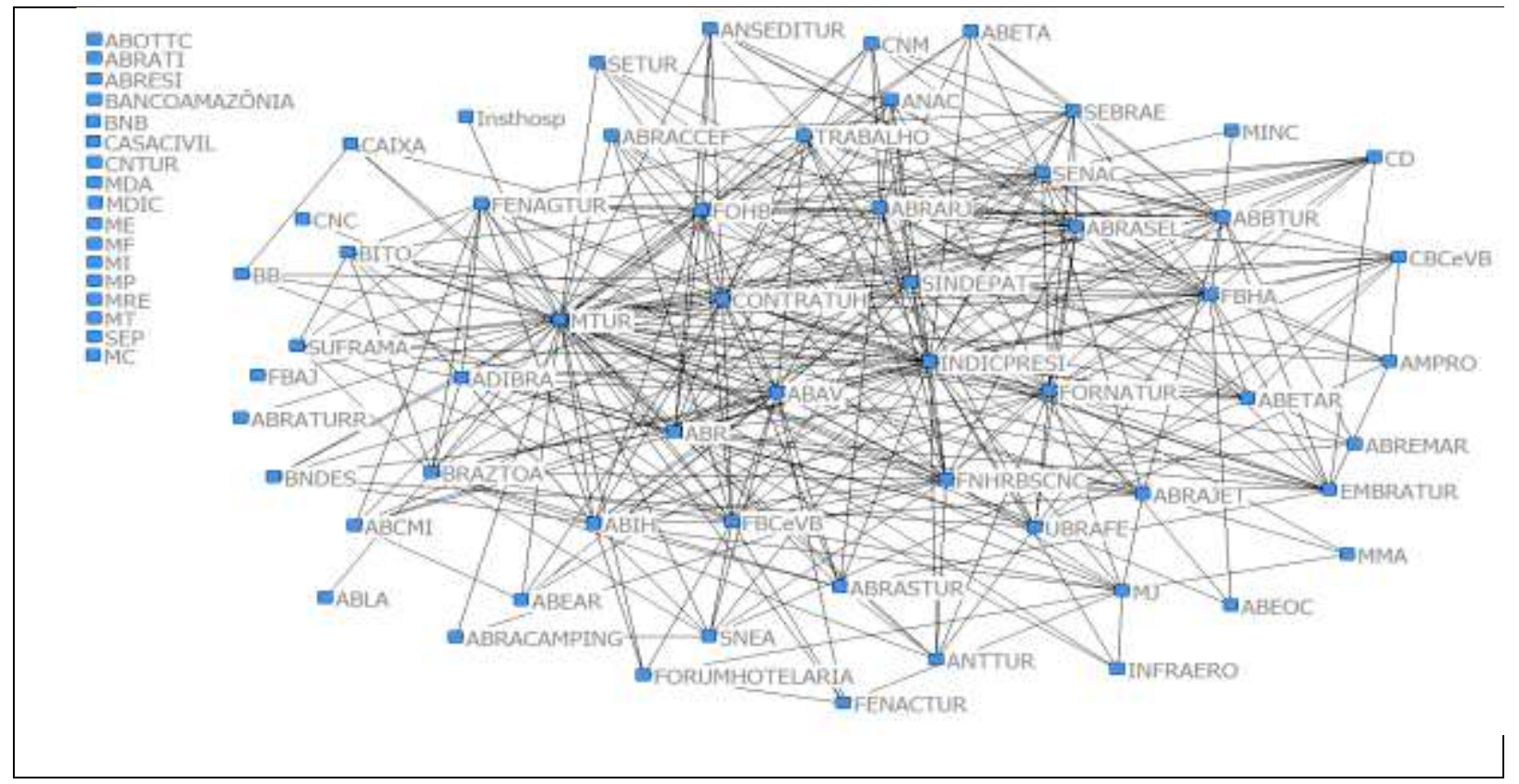

Somam-se aos atores citados, os que aparecem em manifestações de atas do conselho no período de 2003 a 2016 e que não estavam na lista atual, ou seja, os que já participaram de reuniões ordinárias do CNTUR em algum momento, como conselheiros ou convidados. São 2 associações, 2 federações, 1 instituto e 1 sindicato e 0 ator do poder público, nomeadamente, a Secretaria de Turismo do Distrito Federal,

Assim, a rede do CNTUR, estabelecida pela interação observada por meio das atas de reunião ordinária ocorridas de 2003 a 2015, possui um 
total de 75 atores políticos. Desse total, 40 são proativos, ou seja, levaram propostas próprias às reuniões do conselho, 19 somente reagiram a propostas de outros atores e não levaram demandas próprias. Dezessete não interagiram nem propondo nem reagindo às propostas durante 0 período estudado.

A figura 2 apresenta a divisão na rede entre poder público e sociedade. São denominadas entidades da sociedade todas essas empresariais e profissionais que compõe o Conselho Nacional de Turismo. Na figura a seguir, os atores do poder público são os quadradinhos vermelhos e os da sociedade, os verdes. Pela visualização do gráfico podemos perceber a centralidade de três agentes do poder público: MTUR, Indicação da presidência e FORNATUR. É possível ver também, pelo volume de vínculos, a centralidade de algumas entidades da sociedade, como CONTRATUH, Sistema Integrado de Parques e Atrações Turísticas (SINDEPAT), Associação brasileira de bares e restaurantes (ABRASEL) e Fórum de Operadores Hoteleiros do Brasil (FOHB).

Figura 2: Rede de relações do CNTUR dividida entre Sociedade e Poder Público.

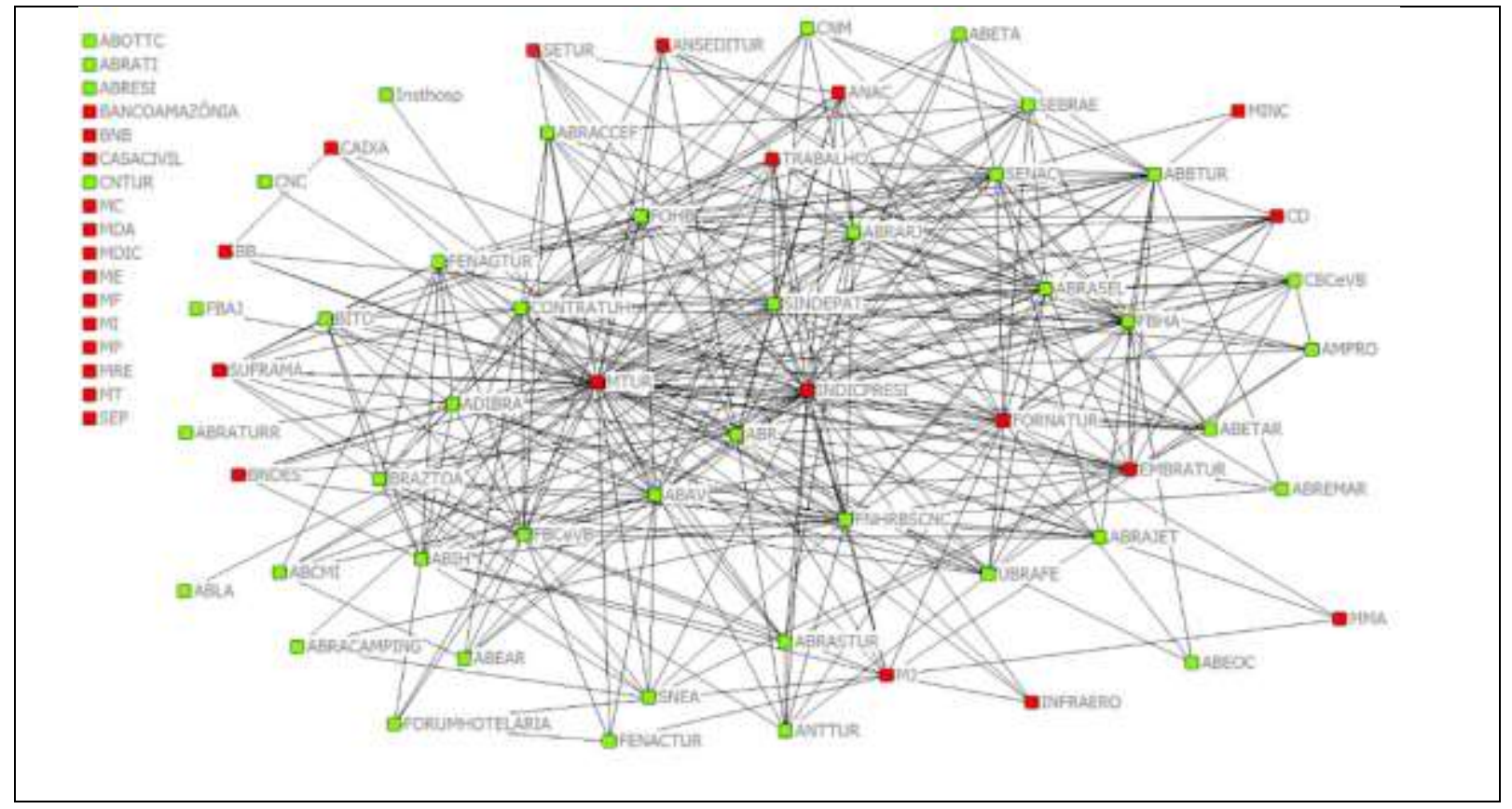

Dos atores que não tem participação registrada em ata de reunião ordinária do conselho no período de 2003 a 2016, 13 são do poder público e 4 da sociedade. Os 17 do poder público e 41 da sociedade participaram pelo menos uma vez das reuniões ordinárias do conselho, de acordo com os documentos da reunião.

A centralidade da rede trata dos atores individuais e sua posição na estrutura, nos quais os centrais localizam-se numa posição que permite acessar e difundir às informações com mais facilidade em relação aos outros atores. (Nooy, 2003; Velazquez, 2005)

Será considerada a centralidade a partir de três medidas: grau de centralidade, intermediação e autovetor. Observa-se no quadro 2 os atores mais centrais na rede do CNTUR:

Quadro 2: Medidas de centralidade dos principais atores da da rede do CNTUR

\begin{tabular}{|l|c|c|c|}
\hline Entidade & Grau de centralidade & Intermediação & Autovetor \\
\hline MTUR & 74.324 & 23.892 & 45.180 \\
\hline INDICPRES & 52.703 & 4.432 & 40.449 \\
\hline SINDEPAT & 40.541 & 2.655 & 32.133 \\
\hline CONTRATUH & 39.189 & 1.598 & 34.027 \\
\hline FOHB & 35.135 & 1.263 & 30.641 \\
\hline ABAV & 33.784 & 1.329 & 28.302 \\
\hline FORNATUR & 32.432 & 2.065 & 27.135 \\
\hline ABRARJ & 33.784 & 1.171 & 29.198 \\
\hline ABR & 31.081 & 1.491 & 26.022 \\
\hline FBHA & 29.730 & 0.813 & 26.184 \\
\hline FNHRBSCNC & 29.730 & 1.227 & 25.285 \\
\hline ABRASEL & 28.378 & 0.544 & 26.119 \\
\hline FBC e VB & 27.027 & 0.771 & 22.987 \\
\hline SENAC & 27.027 & 1.491 & 24.617 \\
\hline ABBTUR & 25.676 & 1.461 & 22.267 \\
\hline ABIH & 24.324 & 0.575 & 21.660 \\
\hline
\end{tabular}

Os atores com maior centralidade são do poder público. O Ministério do Turismo, que para a maioria das reuniões adotou como procedimento padrão responder às proposições dos conselheiros sempre na reunião seguinte, por isso em quase todas as propostas havia participação do MTUR no debate. O ministro do turismo ocupa a presidência do conselho 
e, junto com a Secretária Executiva, coloca-se como responsável por encaminhar as demandas dos conselheiros.

Foram contabilizados como participação do MTUR tanto as falas do ministro, como as do Secretário Executivos, e eventuais secretários do ministério, além disso, o ministério é responsável pelas convocações de reunião. Por esses motivos, o MTUR apresenta-se na rede como um ator extremamente central nas reuniões analisadas. Os ocupantes das duas cadeiras reservadas às indicações da Presidência da República representaram o segundo ator mais central durante o período analisado.

O ministério tem um grau de intermediação superior aos demais atores da rede, o que indica sua capacidade de controle sobre as comunicações que acontecem no conselho durante 0 período estudado. Todas as demandas foram comentadas, respondidas ou propostas pelo ele. $O$ segundo ator em grau de centralidade é o Indicado da presidência, com grau de intermediação, no entanto, bem inferior ao do MTUR, cerca de 5 vezes menor. Esses conselheiros são especialistas no setor turismo e atuaram com frequência propondo e apoiando demandas. Suas atuações não foram analisadas neste trabalho, pois foco foi nos atores representantes da sociedade no conselho.

$\mathrm{Na}$ sétima colocação, quanto ao grau de centralidade está o FORNATUR, criado em 2000. Além disso, é o quarto ator com maior grau de intermediação. É formado por Secretários de Estado de Turismo ou presidentes de órgãos estaduais de turismo. Constitui o chamado núcleo estratégico do turismo, junto com o conselho nacional e o Ministério do Turismo.

Do terceiro ator em diante, por ordem de maior centralidade, considerando as três medidas já citadas, quase todos são representantes não governamentais. O SINDEPAT ocupa a terceira colocação dentre os atores mais centrais no conselho, ou seja, é um ator que tem muitas ligações diretas com outros atores do conselho. É também o agente da sociedade com maior grau de intermediação, fica atrás somente do MTUR e do indicado da presidência. Fundado em 2003 possui 18 parques associados em 9 estados diferentes. Considera sua função como integrativa, além de representativa. (SINDEPAT, 2016)

Uma das três representantes de trabalhadores no conselho, a CONTRATUH ocupa a quarta posição dentre as entidades mais centrais e a segunda entre as entidades não governamentais. Foi fundada em $1988 \mathrm{e}$ suas filiadas são 30 federações e 450 sindicatos em todos os estados do país.

Sindicato é, de acordo com a legislação brasileira, associação que representa categoria profissional ou econômica. Federação significa reunião de grupos profissionais para defender e promover objetivos comuns, no Brasil, denomina-se como federação a associação sindical que reúne cinco ou mais sindicatos representativos de atividades semelhantes. (Ferreira, 2008)

A terceira entidade não governamental mais central nas discussões ocorridas em reuniões ordinárias do CNTUR é o FOHB. Fundada em 2002, possui 28 redes hoteleiras filiadas, de âmbito nacional e internacional, 0 que totaliza 670 hotéis. Presente nas cinco regiões do país, uma de suas funções é representar seus filiados junto ao setor público (FOHB, 2016).

$A$ entidade seguinte à $\mathrm{FOHB}$, em grau de centralidade é a Associação Brasileira de Agências de Viagem (ABAV), que está presente em todos os estados da federação e representa 3.500 agências de viagem. A diretoria da entidade atua de forma permanente junto aos poderes legislativo, executivo e judiciário.

A Associação Brasileira de Revistas e Jornais foi identificada, a partir das atas de reunião ordinária, como de razoável grau de centralidade, no entanto, não foram encontrados dados acerca dos filiados a essa instituição (MTUR, 2013). Por fim, ainda considerada como grau razoável de centralidade -31\%-, a Associação Brasileira de Resorts está presente hoje em 14 estados brasileiros e possui 50 resorts associados. Está, junto ao SENAC, entre as entidades com algum grau de intermediação. (ABR, 2016).

Os graus de intermediação do ministério e dos indicados da presidência mostra que os atores da sociedade consideram o conselho como um canal para interagir com o sistema nacional de turismo, dado isso, a importância que os entrevistados expressam quanto ao funcionamento do conselho. As entidades que se destacaram quanto à centralidade de autovetor, que indica o quanto cada ator mantém contatos distribuídos por todos os grupos da rede, considerando a estrutura geral, são os mesmos atores que se destacam pelo grau de centralidade.

É perceptível a diversidade das entidades que compõe o conselho ao observar inicialmente essas entidades de maior centralidade. As representações são desiguais quanto à temática, ao papel de cada um no setor e aos filiados. É possível identificar quatro grupos principais de organizações da sociedade dentre os que são ativos no conselho. Os grupos quanto à centralidade e proatividade no conselho são descritos a seguir.

O primeiro grupo é central e propositivo, ou seja, é composto por aquelas organizações que possuem alta centralidade e que levaram demandas ao conselho em maior quantidade (grau de centralidade acima de 30 e iniciativa de pelo menos 6 demandas). As organizações que atuaram no conselho levando mais demandas para discussão nas reuniões e que foram centrais são: CONTRATUH, Associação Brasileira de Revistas e Jornais (ABRARJ), ABAV e FORNATUR.

Um segundo grupo é central e pouco propositivo, composto por organizações que possuem alto grau de centralidade e que levaram menos demandas (grau de centralidade acima de 30 e iniciativa de menos de 6 demandas). Essas são as organizações que costumam participar com frequência dos debates sobre demandas levadas ao conselho por outros atores. Entre essas há as de maior grau de centralidade: SINDEPAT, FOHB e a Associação Brasileira de Resorts (ABR).

Outro grupo é composto por atores pouco centrais, mas propositivos: (grau de centralidade abaixo de 30 e iniciativa de pelo menos 6 demandas). As organizações que compõe esse grupo são: ABBTUR, FENAGTUR, ABRAJET e BRAZTOA. Por fim, um quarto grupo é formado pelas entidades que não são centrais e propõe demandas com pouca frequência (grau de centralidade abaixo de 30 e iniciativa de menos de 6 demandas),mas podem ser consideradas atuantes no conselho frequentam as reuniões e possuem registros de participação tanto na proposição quanto no debate. São exemplos ABRASEL, Federação Brasileira de Hospedagem e Alimentação (FBHA) e a Confederação Nacional do Comércio de Bens, Serviços e Turismo (CNC).

\section{CONSIDERAÇÕES FINAIS}

Foi realizada a análise documental das atas de reunião ordinária do CNTUR e separadas as informações a respeito de quais foram as 
demandas levadas ao conselho de 2003 a 2015. Registradas as informações acerca de quem as fez e quem discutiu cada uma delas, foram identificadas 200 solicitações propostas e discutidas no conselho ao longo do período considerado. Dessas, 45 referem-se às normas legais, objeto de análise neste trabalho. Os outros temas debatidos foram gestão no Sistema Nacional de Turismo, capacitação e pesquisas na área, financiamento e orçamento, demandas setoriais diversas e funcionamento interno do conselho.

Percebeu-se que a maior quantidade de demandas foi proposta por conselheiros do segmento governamental - MTUR-, indicado da presidência da república e Fórum nacional dos secretários e dirigentes estaduais. Por outro lado, as entidades da sociedade que mais levaram demandas foram as três únicas representantes de profissionais CONTRATUH, FENAGTUR E ABBTUR-, embora a maioria dos representantes da sociedade no conselho pertençam ao segmento empresarial.

Com a sistematização dessas informações, foi possível construir a rede social do conselho. Percebe-se, então, que seus atores com maior centralidade são o próprio MTUR e as duas vagas de indicação da presidência da república. Isso deve-se ao fato de que grande parte da pauta das reuniões ser constituída por apresentações do ministério, que fez sempre o esforço de responder às demandas dos conselheiros, o que foi computado como debate e aumenta o grau de centralidade do ator político.

Dentre as entidades da sociedade com maior centralidade, as três primeiras foram SINDEPAT, CONTRATUH e FOHB. As outras duas representantes de profissionais, apontadas como as que mais levaram demandas às reuniões do conselho, têm grau de centralidade bem menor.

Foram observados quatro grupos de entidades da sociedade no conselho. Um central e propositivo, que possui alto grau de centralidade e é composto por aquelas organizações que levaram maior quantidade de demandas ao conselho; outro também central, mas pouco propositivo, com alto grau de centralidade, composto por organizações que levaram menos demandas; um composto por atores pouco centrais, mas propositivos; e por fim o grupo das entidades que não são centrais e propõe demandas com pouca frequência, mas podem ser consideradas atuantes no conselho por terem frequentado as reuniões e possuírem registros de participação tanto na proposição quanto no debate.

Entidades que compõe o conselho têm diversas propostas individuais ou coletivas, mas não se tornam consenso ou deliberação. Assim, elas levam propostas ao conselho, ao poder legislativo, aos atores políticos, aos órgãos do poder executivo que participam ou que não participam do conselho. A sociedade não dialoga em bloco com o governo nos conselhos a quantidade de demandas setoriais muito específicas, em detrimento das que abrangem o setor de forma ampla demonstra a quão separada é a atuação das entidades analisadas.

\section{REFERÊNCIAS.}

Associação Brasileira de Resorts. (2016) [Página da ABR] Recuperado em 18/8/2016 de: http://abr-resortsbrasil.com.br/.

Bonafont, L C (2014). Redes de Políticas Públicas. Madrid: Siglo Vientiuno de Espana Editores.

Borgatti, S. P. \& Cross, R. (2003) A relational view of information seeking and learning in social networks. Management Science 49:432-45.

Brandão, P. M. (2010) Análise da rede política do turismo brasileiro. Universidade Federal do Rio Grande do Norte /Centro de Ciências Sociais Aplicadas /Programa de Pós-Graduação em Turismo. Dissertação. Natal

Brandão, P. M. (2014). Os efeitos da democraticidade dos espaços públicos participativos sobre o desempenho de destinos turísticos. Universidade Federal da Bahia. Escola de administração. Núcleo de Pós-Graduação em Administração NPGA Tese. Salvador.

Burt, R. S., Kilduff, M. \& Tasselli, S. (2013) Social Network Analysis: Foundations and Frontiers on Advantage. Annu. Rev. Psychol. 64:527-47.

Cândido, S. E. A., Sacomano, M. \& Côrtes, M. R. (2015) Campos e redes na análise das organizações: explorando distinções teóricas e complementaridades metodológicas. Revista Eletrônica Gestão \& Sociedade, v.9, n.24, p. 1073-1097 Setembro/Dezembro.

Cavalcanti, P. A. B. (2006). Um olhar crítico sobre o Conselho Nacional de Turismo: Articulação do Setor, Legitimidade e Auto-Interesse na Construção das Políticas Públicas. Fundação Getúlio Vargas - EAESP. Dissertação. São Paulo.

Conselho Nacional de Turismo (2016). [Página do CNTUR] Recuperado em 11.2.2016 de http://www.turismo.gov.br/conselho-nacional-de-turismo.html.

Donati, P. (2015) Manifesto for a critical realist relational sociology. International review of sociology. (25) 86-109. 2015.

Fórum de Operadores Hoteleiros do Brasil (2016) [Página da FOHB]. Recuperado em 16/8/2016 de http://fohb.com.br/sobre-nos/quem-somos/

Hanneman, R. A. \& Riddle, M. (2005) Introduction to social network methods. Riverside, CA: University of California.

Ingold, K \& Leifeld, P. (2016) Structural and Institutional Determinants of Influence Reputation: A Comparison of Collaborative and Adversarial Policy Networks in Decision Making and Implementation. J Public Adm Res Theory 26 (1): 1-18.

Marques, E. C. (1999) Redes sociais e instituições na construção do estado e da sua permeabilidade. Revista Brasileira de Ciências Sociais Vol. 14 no 41.

Ministério do Turismo. (2013) Portaria n. 225, de 30 de agosto de 2013. [Designar os integrantes do Conselho nacional de turismo - $\mathrm{CN}$, representantes da iniciativa privada de âmbito nacional]. Brasília.

Nooy, W. (2003) Fields and networks: correspondence analysis and social network analysis in the framework of field theory. Poetics 31, 305-327.

Nooy, W., Mrvar, A. \& Batagel, J. (2005) Exploratory Network Analysis with Pajek. University Press, New York, 2005.

Oganauskas, D. S. N. (2014) A participação no conselho nacional de turismo: reflexos da relação com o ministério do turismo. Programa de Pós-Graduação em Políticas Públicas, Universidade Federal do Paraná. Dissertação.

Reyes, E. Jr. (2012). As relações interpessoais em redes de apoio ao terceiro setor. Universidade do Vale do Rio dos Sinos - UNISINOS. Programa de Pós-Graduação em Administração. Tese. São Leopoldo.

Silveira, D. T. \& Gerhardt, T. E. (2009) (orgs) Métodos de pesquisa. Porto Alegre, Ed UFRGS, 2009

Sistema Integrado de Parques e Atrações Turísticas (2016). [Página da SINDEPAT] Recuperado em 18/8/2016 de: http://www.sindepat.com.br/site/sindepat.asp.

Tasselli, S., Kilduff, M. \& Menges, J. I. (2015) The Microfoundations of Organizational Social Networks: A Review and an Agenda for Future Research. Journal of Management. Vol. 41 No. 5, 1-27.

Velázquez, Á. O. A. \& Norman, A. G. (2005) Manual Introdutório à Análise de Redes Sociais: exemplos práticos com UCINET 6.109 e NETDRAW 2.28. Universidad Autônoma de Estado de México. 